\title{
Do mechanism-based social explanations make a case for methodological individualism?
}

Jeroen Van Bouwel

(presented at EPSA2015, Duesseldorf)

In the recent philosophy of social science literature, we notice an increasing support for mechanism-based social explanations. Earlier pleas for social mechanisms used to be closely linked to defenses of methodological individualism. However, more recent contributions seem to be loosening that link and developing a more sophisticated account - ascribing a less important role to micro-foundations (e.g. Ylikoski 2012, Little 2012). In this paper, I want to review the impact of the mechanism-approach on methodological individualism and draw more radical conclusions as regards the individualism/holism debate, severing the link between the social mechanisms-approach and individualism. Four steps will be taken:

(a) We should consider more than two levels of social explanation.

Several advocates of the mechanism-based approach to social explanations have been defending the relative explanatory autonomy of meso-level explanations (e.g. Little, 2012). This adds a welcome extra explanatory level in between the individualist micro-level and the macro-level. As such, it supersedes the dichotomous thinking in the individualism/holism debate in which there would always be an individual micro-level - which would always be the same (cf. point (b) below) - that is contrasted with a macro-level.

(b) The levels of explanation are perspectival levels; neither absolute, nor unique.

However, the advocacy of meso-level explanations still comes with a microfoundations requirement. Let us first zoom in on microfoundations (for the requirement, see step (c) below). In the philosophy of social science debate, the microfoundations are usually understood as individual-level microfoundations, see, for instance, most recent work on analytical sociology. It is presupposed that there is some comprehensive, unique, and privileged individual level, the level of individual actors (cf. Ylikoski 2012). However, microfoundations do not necessarily have to be understood in that way. They could also just be understood as looking for foundations on any lower-level, e.g., on a sub-individual level focussing on cognitive capacities and processes that might be important in explaining certain social phenomena. The latter understanding of microfoundations would be more in line with actual social scientific practice in which we notice that the specification and amount of levels of explanation is perspectival, depending on the phenomena, research approaches and explanatory interests involved. Thus, the micro in microfoundations should be understood as perspectival too, rather than absolute or unique. 


\section{(c) Seeking for microfoundations ánd seeking for macrofoundations are good heuristics.}

Next, let us scrutinize the microfoundations requirement. This requirement stipulates "that all social facts, social structures, and social causal properties depend ultimately on facts about individuals within socially defined circumstances. Social ascriptions require microfoundations at the level of individuals in concrete social relationships." (Little 2012, p.138) Advocates of the social mechanisms approach have often been defending that a macro-explanation would never be satisfactory, or, could only be satisfactory if a micro-level part of the social explanation was provided, e.g. Hedström and Swedberg (1998). Thus, they consider a reference to (individual actions on) the individual, micro-level as a condition sine qua non of a satisfactory explanation.

Daniel Little develops a different position. According to him, the microfoundations requirement should not be understood as a condition for satisfactory explanations, but rather as a form of confirmation or justification of a macro-explanation (cf. Little 2012). Here as well Little takes into account the actual explanatory practice of social scientists and he avoids the ontological fallacies (i.e., mixing up ontological and explanatory issues) made by earlier advocates of microfoundations. However, Little's requirement remains vague. It should be understood as constraining explanatory practice, but how would that exactly work? How is the microfoundations requirement operationalised (and how would it interfere with our explanatory practice)?

Petri Ylikoski (2012) ascribes a special role to microfoundations as explanantia of constitutive explanations. I will give counterexamples that question this alleged special role.

In short, the more recent accounts of the microfoundations requirement are more sophisticated than earlier accounts, but they still remain problematic as I will show. A fruitful role one could see for a microfoundations pursuit is as an engagement to compare one's own explanatory practice and research approach with other practices and approaches. This might result in more interaction between different approaches through which approaches articulate themselves and their relations to others more explicitly and through which the strengths and weaknesses of the respective approaches are clarified. In this respect, we could not only encourage seeking for microfoundations as a heuristic, but, on the same basis, propose searching for macrofoundations as a fruitful heuristic. (Some use the term macrofoundations, but given that we think of it as something higher up, one could also use macro-roof or macro-covering.)

(d) there are no general preference rules with respect to the level of social explanations.

This brings me to the fourth step in which we have to draw more radical conclusions than Little and Ylikoski as concerns the impact of the social mechanisms-approach on methodological individualism and sever the link between the social mechanisms-approach and individualism. The social mechanisms approach has a lot to offer to help clarifying the explanatory reasoning going on in social science, but it cannot be used to make a case for methodological individualism. The special role ascribed to microfoundations by defenders of mechanism-based social explanations cannot be upheld. We have to conclude that there are 
neither general preference rules with respect to the level of social explanations, nor good reasons for a general microfoundations requirement.

I will defend that the debate on social mechanisms, microfoundations, explanatory autonomy, etc. should not be so much about developing the ultimate individualistic approach or holistic approach, but rather about understanding explanatory reasoning in social science and optimize the way in which different explanatory approaches interact, coexist, can be integrated and/or develop some division of labour among each other, while making the best out of the strengths and limitations of the respective explanatory strategies of holists and individualists. Philosophers of social science might contribute in analyzing, visualizing and optimizing the interaction among these different approaches (as an example I will discuss Longino 2013 and some of my earlier work, cf. Van Bouwel, 2004, 2010, 2014, and Van Bouwel \& Weber, 2002, 2008a, 2008b).

\section{References.}

Hedström, P. and R. Swedberg (eds.). 1998. Social mechanisms. Cambridge UP.

Little, D. 2012. Explanatory Autonomy and Coleman's Boat. Theoria 74: 137-151

Longino, H. 2013. Studying Human Behavior. University of Chicago Press.

Van Bouwel, J. 2004. Individualism and holism, reduction and pluralism. Philosophy of the Social Sciences, 34, 527-535.

Van Bouwel, J. 2010. Why social emergence? Discussing the use of analytical metaphysics in social theory. In R. Vanderbeeken \& B. D'Hooghe (Eds.), Worldviews, science and us: Studies of analytical metaphysics (pp. 153-167). Singapore: World Scientific.

Van Bouwel, J. 2014. Explanatory Strategies beyond the Individualism/Holism Debate. In J. Zahle and F. Collin (eds.) Rethinking the Individualism/Holism Debate: Essays in the Philosophy of Social Science. Berlin: Springer.

Van Bouwel, J., \& Weber, E. 2002. Remote causes, bad explanations? Journal for the Theory of Social Behaviour 32: 437-449.

Van Bouwel, J., \& Weber, E. 2008a. A pragmatic defense of non-relativistic explanatory pluralism in history and social science. History and Theory 47: 168-182.

Van Bouwel, J., \& Weber, E. 2008b. De-ontologizing the debate on social explanations: A pragmatic approach based on epistemic interests. Human Studies 31(4): 423-444.

Ylikoski, P. 2012. Micro, Macro, and Mechanism. In The Oxford Handbook of Philosophy of Social Science. ed. H. Kincaid, 21-45. Oxford University Press. 